\title{
Threshold Levels of Visual Field and Acuity Loss Related to Significant Decreases in the Quality of Life and Emotional States of Patients with Retinitis Pigmentosa
}

\author{
Line Azoulay ${ }^{a, c}$ Philippe Chaumet-Riffaud ${ }^{a}$ b Steven Jaron ${ }^{a}$ Camille Roux ${ }^{a}$ \\ Serge Sancho ${ }^{a}$ Naomi Berdugo ${ }^{a, d}$ Isabelle Audo ${ }^{a, c, d}$ José-Alain Sahel ${ }^{a, c, d}$ \\ Saddek Mohand-Saïd ${ }^{a, c, d}$ \\ aCentre Hospitalier National d'Ophtalmologie des Quinze-Vingts, DHU ViewMaintain, INSERM-DHOS CIC 1423, \\ ${ }^{b}$ Centre Hospitalier de Bicêtre, Assistance Publique-Hôpitaux de Paris, Université Paris Sud-11, CINSERM U968, and \\ ${ }^{\mathrm{d}}$ Institut de la Vision, Sorbonne Universités, UPMC Université Paris-06, UMR_S 968, Paris, France
}

\section{Key Words}

Retinitis pigmentosa $\cdot$ Quality of life $\cdot$ Emotional state .

Visual field $\cdot$ Visual acuity

\begin{abstract}
Introduction: Retinitis pigmentosa (RP) is an inherited retinal disorder, characterized by photoreceptor degeneration inducing progressive vision loss. This study evaluates its impact on quality of life (QOL) and emotional states of patients affected by RP. Methods: A cross-sectional study was conducted on $60 \mathrm{RP}$ patients diagnosed with rod-cone dystrophy and on 20 control subjects. The RP population has been divided into 3 groups according to visual field (VF) and visual acuity (VA) impairments. Concurrently, scores of selfreported QOL (25-item National Eye Institute Visual Functioning Questionnaire) and of the Hospital Anxiety and Depression Scale for anxiety/depression assessments were collected. Results: For the QOL composite score, we noticed consistent differences between all VF and VA affected groups and their control group. We also found significant differences between both the most affected VF group (VF1: ØVF $<20^{\circ}$ ) and VA group (VA1: VA <0.3) compared to other VF and VA
\end{abstract}

groups. For anxiety/depression scores, consistent differences have been found between the control group and VF1 and VA1, respectively. Conclusions: This work determines that, for RP patients, a significant QOL and emotional state deterioration correlates with a residual VF diameter below $20^{\circ}$ and a VA lower than 0.3. It introduces, for the first time, thresholds to be used in visual restoration or visual preservation therapies to improve QOL of RP patients.

ㄷ) 2015 S. Karger AG, Basel

\section{Introduction}

Retinitis pigmentosa (RP) is a group of inherited retinal diseases which induce photoreceptor (rods and cones) degeneration leading to progressive visual loss $[1,2]$. These diseases are characterized by a great heterogeneity from both genetic and clinical points of view [1,3-5]. In most cases, RP provokes rod photoreceptor degeneration, responsible for defective dark adaptation (night

The work was conducted in the clinical investigation center CIC 1423 in the Quinze-Vingt Hospital, in Paris.

\begin{tabular}{ll}
\hline KARGER 125/5 & $\begin{array}{l}\text { ○ 2015 S. Karger AG, Basel } \\
0030-3747 / 15 / 0542-0078 \$ 39.50 / 0 \quad \text { Karger }\end{array}$ \\
E-Mail karger@karger.com caccess \\
www.karger.com/ore & $\begin{array}{l}\text { Thisis an Open Access article licensed under the terms of the } \\
\text { Creative Commons Attribution-NonCommercial 3.0 Un- } \\
\text { ported license (CC BY-NC) (www.karger.com/OA-license), } \\
\text { applicable to the online version of the article only. Distribu- } \\
\text { tion permitted for non-commercial purposes only. }\end{array}$
\end{tabular}

Saddek Mohand-Saï

CHNO des Quinze-Vingts, Inserm CIC 1423

28 rue de Charenton

FR-75012 Paris (France)

E-Mail smohand-said@ quinze-vingts.fr 
blindness). The major handicap induced by RP, however, relates to the later loss of cone photoreceptors, which ineluctably results in peripheral visual field (VF) impairment. Finally, the disease progression can affect the central vision and induce total blindness.

In addition to sensory damage, vision loss generates many social and psychological repercussions impacting the quality of life (QOL) of individuals with visual impairment. Evaluation of the QOL has gradually taken its rightful place in ophthalmology with the development of several questionnaires since 1980. It has increasingly been implemented to evaluate the real impact of visual function troubles on patients' daily lives and to improve patient management.

The evaluation of the QOL becomes particularly useful in the early phase clinical trial (https://clinicaltrials.gov) where patients have limited residual vision to assess the positive contribution or the side effects of new therapies. It is mandatory to know the real clinical impacts of a significant change in a surrogate end point such as a VF or visual acuity (VA) improvement. Previous studies have demonstrated correlations between the degree of VF, VA loss and QOL, showing that QOL decreases proportionally to the loss of visual function [6-9].

In our study, we have extended the correlation analyses between visual loss and QOL in order to determine a transitional level of vision that can represent a threshold for preservative therapeutic approaches or restorative strategies.

\section{Methods}

A cross-sectional study has been conducted on 60 patients diagnosed with typical RP 'rod-cone dystrophy' who were referred to the Reference Center for Hereditary Retinal Dystrophy/Clinical Investigation Center (Inserm CIC 1423/Quinze-Vingt Hospital, Paris [10]). A control group of 20 age-matched healthy subjects with no systemic or ocular disease in terms of VF impairment (VF groups) and VA loss (VA groups) have been set.

Participants were all 18 years old or more, French speakers with no systemic or ocular disease apart from the ones studied. Functional ocular evaluations such as monocular and binocular VF assessments and VA measurements have been performed. The 25item National Eye Institute Visual Functioning Questionnaire (NEI-VFQ-25), QOL survey and the Hospital Anxiety and Depression Scale (HADS) questionnaire assessment of the patients' emotional states were self-administered and completed by each participant (or when needed by one of their relatives).

This study follows the tenets of the Declaration of Helsinki. Informed consent was obtained from all patients and normal subjects after explanation of the study. The protocol has been approved by an institutional review board: CPP (Persons Protection Committee in French) Ile de France V, Project 06693, EUDRACT 2006-A00347-44.

Impact of Visual Loss on the QOL and Emotional States in RP

\section{Visual Field}

VF was assessed by monocular and binocular VF Goldmann kinetic manual perimetry [11]. The study population included patients with monocular and binocular VF restricted to the central area (i.e. patients lacking some peripheral retinal sensitivity) using isopter V4 for monocular and isopter III4 for binocular VF, respectively. Patients have been classified into VF groups according to their binocular VF. The choice of VF without peripheral islands allowed to have homogenous patient groups and to avoid the too great variability that can be induced by the diversity of sizes, locations and sensibilities of remaining peripheral islands. We have considered that normal binocular VF consists of a horizontal 120-degree-wide area bordered on each side by a monocular 30-degree-wide visual area. Binocular VF assessment is legal reference in France to determine functional capacity in a forensic or professional context, according to Decree No. 921216 published in the Official Journal of November 4, 1993.

The RP population has been divided into the following $3 \mathrm{VF}$ groups, each including 20 subjects: VF1, with a residual binocular $\mathrm{VF}$ of less than $20^{\circ}$ in diameter $\left(\varnothing \mathrm{VF}<20^{\circ}\right)$; VF2, with a residual binocular VF between 20 and $40^{\circ}$ in diameter $\left(20^{\circ} \leq \varnothing \mathrm{VF} \leq 40^{\circ}\right)$; VF3, with a residual binocular VF larger than $40^{\circ}$ in diameter $\left(\varnothing \mathrm{VF}>40^{\circ}\right)$. The VF groups were compared to the control group of 20 healthy subjects without any VF restrictions (VFC group).

Visual Acuity

The Early Treatment Diabetic Retinopathy Study (ETDRS) logarithmic scale has been used to evaluate VA at a distance of 4 $\mathrm{m}$. Except in a few cases where a slight difference was observed, the VA was comparable in both eyes. The RP patients have been divided into the following $3 \mathrm{VA}$ groups, based on best eye VA: VA1 where VA $\leq 0.3$ (15 patients); VA2 where $0.3<\mathrm{VA} \leq 0.7$ (21 patients); VA3 where VA $>0.7$ (24 patients). The VA groups have been compared to the control group of 20 healthy subjects where VA was equal to 1 (VAC group).

\section{The 25-Item National Eye Institute Visual Function}

\section{Questionnaire}

The NEI-VFQ-25 was developed in the late 1990s to assess various dimensions of QOL in subjects with visual loss, including psychological and subjective aspects. It is reliably and significantly correlated with the NEI-VFQ-51 original version $[12,13]$. The NEI-VFQ-25 was validated for various eye diseases, and it is among the most used and valuable psychometric tools [14-18].

It is made up of 25 questions that address 12 aspects of daily living: general health, general vision, near vision, distance vision, driving, peripheral vision, color vision, ocular pain, role limitation, dependency, social function and mental health. We used a French translated version validated for glaucoma and ocular hypertension [19]. Patients answered the questionnaires themselves without any interviewer. The answer to each of the 25 questions has been converted into a 100-point scale, in which 100 represents the best possible score. Results were distributed according to 12 subscores covering each of the 12 individual domains and a composite score (CS) representing the mean score of all subscores, except for general health which is not directly related to the visual condition [20].

\section{The Hospital Anxiety and Depression Scale}

The HADS questionnaire evaluates patients' anxiety-depression scores to determine their emotional state [21]. The reliability 
Table 1. Scores of the 3 groups of RP patients according to VF and control group

\begin{tabular}{lllll}
\hline Scores & $\begin{array}{l}\text { VF1 } \\
(\mathrm{n}=20)\end{array}$ & $\begin{array}{l}\text { VF2 } \\
(\mathrm{n}=20)\end{array}$ & $\begin{array}{l}\text { VF3 } \\
(\mathrm{n}=20)\end{array}$ & $\begin{array}{l}\text { VFC } \\
(\mathrm{n}=20)\end{array}$ \\
\hline CS & $37.7[19.7]$ & $55.9[22.6]$ & $60.8[24.4]$ & $93.7[7.8]$ \\
Anxiety & $10.0[3.5]$ & $9.50[6.3]$ & $9.0[4.3]$ & $6.50[2.3]$ \\
Depression & $7.0[7.0]$ & $4.50[6.3]$ & $4.0[5.5]$ & $2.00[3.5]$ \\
\hline
\end{tabular}

Values are presented as medians with interquartile ranges in square brackets. RP VF groups: VF1, ØVF $<20^{\circ}$; VF2, $20^{\circ} \leq \varnothing \mathrm{VF}$ $\leq 40^{\circ}$; VF3, ØVF $>40^{\circ}$; VFC $=\mathrm{VF}$ control group.

of the questionnaire has been confirmed in numerous studies, among them two reviews $[22,23]$ including 200 and 747 relevant studies, respectively. We used a French translated version introduced in a validation study by Lépine et al. [24]. The questionnaire is composed of 14 questions ( 7 for the anxiety score and 7 for the depression score). Each item is noted on a $0-3$ scale according to a reading grid. The anxiety or depression diagnosis is negative below 7 , low between 8 and 10, and positive above 11 .

\section{Statistical Analysis}

Analysis of the data has been performed using the Statistical Package for the Social Sciences (SPSS, version 19.1, IBM Corporation). All statistical tests were carried out with significant level of risk set at $\alpha=5 \%$, or less in case of repeated Mann-Whitney, using Bonferroni correction tests, in order to preserve a global risk of $\alpha=0.05$. Except for age, analyses of data showed they did not comply with normal distributions, so we used nonparametric tests.

The test of Spearman correlations was performed between all subscores of NEI-VFQ-25.

Comparisons of the frequency distribution for categorical variables of sex were performed with Pearson's $\chi^{2}$ test between VF and VA groups. Age comparison was performed with a 1-factor analysis of variance.

A Kruskal-Wallis test was carried out to compare ranks of variables (CS, anxiety and depression scores) between VF and VA groups. In case of a significant difference between the 4 groups, post hoc tests were conducted.

In addition, within each VF group, QOL scores were compared according to patients' VA groups with the Kruskal-Wallis test. Similarly, within each VA group, QOL scores were analyzed according to patients' VF groups with the Kruskal-Wallis test.

\section{Results}

The demographic analysis of populations showed no significant difference within VF or VA groups in terms of age and gender. The average population age was 44 years $( \pm 14, \mathrm{SD})$ for RP and 41 years $( \pm 13)$ for the control population.

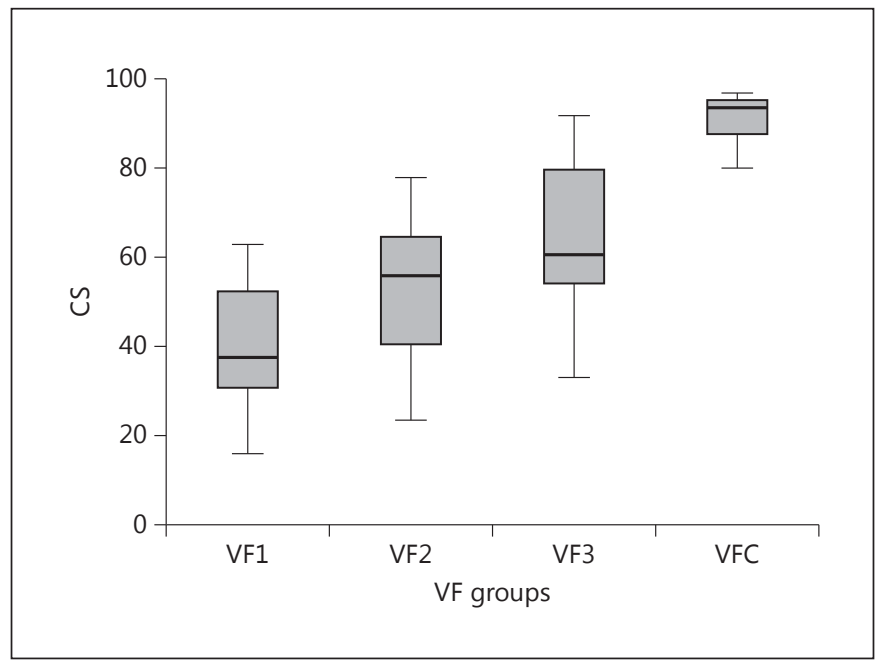

Fig. 1. Distribution of CS in the VF and VFC groups. RP VF groups: $\mathrm{VF} 1, \varnothing \mathrm{VF}<20^{\circ}$; VF2, $20^{\circ} \leq \varnothing \mathrm{VF} \leq 40^{\circ}$; VF3, $\varnothing \mathrm{VF}>40^{\circ}$. The line in the box plot is the median, which is surrounded by a box the top and bottom of which indicate the interquartile range (the limits within which the middle $50 \%$ of observations fall). The distance between the extreme values and box plot represent $25 \%$ higher values and $25 \%$ lower values.

The CS and anxiety/depression scores of VF groups (median and interquartile range) are shown in table 1.

When comparing the CS values between the VFC group and the RP VF groups (table 1), a significant difference was found between groups (Kruskal-Wallis test for CS; $\mathrm{p}<0.001$ ). It appears, in figure 1 , that CS in VFC is markedly above RP VF groups, and, in all VF groups, CS gradually decreased with severity of VF impairment. There was a significant difference in CS between groups VF1 and VF2 ( $p=0.013$; table 2$)$ that also revealed marked differences between VF1 and groups VF3 and VFC.

A significant difference was evaluated between groups VF3 and VFC ( $p<0.001$; table 2$)$. The data distributions shown in figure 1 suggest significant differences also between groups VF2 and VFC. The CS values for groups VF2 and VF3 did not differ significantly.

For anxiety and depression scores, an overall significant difference has been seen between VF groups and $\operatorname{VFC}(\mathrm{p}=0.004$ and $\mathrm{p}=0.004$, respectively). The median scores for the groups are shown in table 1. Between-group comparisons of anxiety scores (table 2 ) showed significant differences between groups VF2 and VFC ( $\mathrm{p}=$ $0.004)$. Consequently, the anxiety score was different between groups VF1 and VFC. No significant difference was revealed between groups VF1 and VF3 and between
Azoulay et al. 
Table 2. Results of post hoc tests (Mann-Whitney) comparing CS between VF groups and control group

\begin{tabular}{lllllll}
\hline Scores & VF1-VF2 & VF1-VF3 & VF2-VF3 & VF1-VFC & VF2-VFC & VF3-VFC \\
\hline CS & $0.013^{*}$ & - & 0.070 & - & - & $<0.001^{*}$ \\
Anxiety & - & 0.355 & - & - & $0.004^{*}$ & 0.020 \\
Depression & - & 0.087 & - & $0.001^{*}$ & 0.045 & 0.022 \\
\hline
\end{tabular}

RP VF groups: VF1, ØVF $<20^{\circ}$; VF2, $20^{\circ} \leq \varnothing \mathrm{VF} \leq 40^{\circ}$; VF3, $\varnothing \mathrm{VF}>40^{\circ} .{ }^{*}$ Significance threshold: $\mathrm{p}<0.0167$ for CS and anxiety score and $\mathrm{p}<0.0125$ for depression score. Post hoc test: Mann-Whitney.

Table 3. Scores of the 3 RP groups according to VA level and control group

\begin{tabular}{lcccc}
\hline Scores & $\begin{array}{l}\text { VA1 } \\
(\mathrm{n}=15)\end{array}$ & $\begin{array}{l}\text { VA2 } \\
(\mathrm{n}=21)\end{array}$ & $\begin{array}{l}\text { VA3 } \\
(\mathrm{n}=24)\end{array}$ & $\begin{array}{l}\text { VAC } \\
(\mathrm{n}=20)\end{array}$ \\
\hline CS & $37.4[19.2]$ & $56.1[18.6]$ & $59.8[21.7]$ & $93.73[7.8]$ \\
Anxiety & $11.0[7.0]$ & $10.0[4.0]$ & $9.0[4.0]$ & $6.50[2.3]$ \\
Depression & $7.0[6.0]$ & $6.0[7.0]$ & $4.0[6.3]$ & $2.00[3.5]$ \\
\hline
\end{tabular}

Values are presented as medians with interquartile ranges in square brackets. RP VA groups: VA1, VA $<0.3$; VA2, $0.3<\mathrm{VA} \leq$ 0.7 ; VA3, VA $>0.7$; VAC = control group.

groups VF3 and VFC. So, table 1 does not suggest any difference between VF2 and the 2 other VF groups. For depression scores, the difference was statically significant only between group VF1 and control group VFC ( $p=$ 0.001 ) with no differences between the VF groups (table 2). As mentioned in the Methods section, in order to homogenize the RP VF groups, we have chosen VF without peripheral sensitivity. Additional analyses were performed to visualize the possible impact of peripheral islands (see online suppl. file; www. karger.com/doi/10.1159/000435886).

When comparing VA groups and the control group VAC (table 3), there was a significant difference in CS between the 4 groups $(\mathrm{p}<0.001)$.

The analysis of distribution showed that median CS decreases with the severity of VA impairment (fig. 2). A significant difference was found between group VA1 and group VA2 ( $\mathrm{p}=0.0047$; table 4$)$. Data distributions shown in figure 2 suggest the existence of significant differences between group VA1 versus group VA3 and control group VAC. Moreover, statistical analysis revealed a significant difference between groups VA3 and VAC $(\mathrm{p}<0.001$; table 4).

Impact of Visual Loss on the QOL and Emotional States in RP

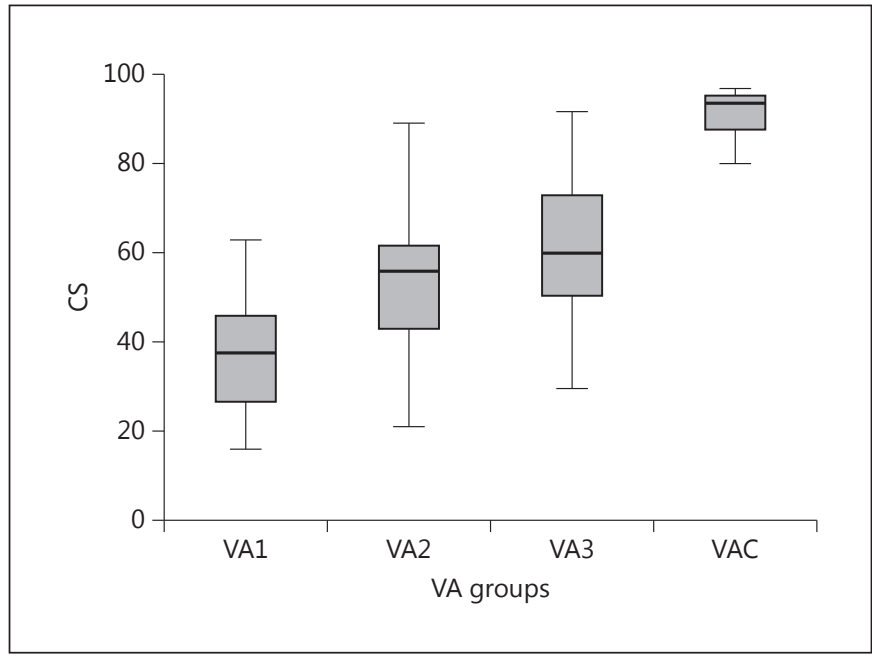

Fig. 2. Distribution of $\mathrm{CS}$ in the VA and VAC groups. RP VA groups: VA1, VA $<0.3$; VA2, $0.3<\mathrm{VA} \leq 0.7$; VA3, VA $>0.7$. The line in the box plot is the median, which is surrounded by a box the top and bottom of which indicate the interquartile range (the limits within which the middle $50 \%$ of observations fall). The distance between the extreme values and box plot represent $25 \%$ higher values and $25 \%$ lower values.

Data distribution in figure 2 also shows a difference between groups VA2 and VAC. Groups VA2 and VA3 did not show any significant difference.

Anxiety and depression scores were significantly different between the 3 VA groups and VAC ( $p=0.005$ and $\mathrm{p}=0.003$, respectively), the medians are shown in table 3. For anxiety scores, we noted a significant difference between groups VA3 and VAC ( $\mathrm{p}=0.0065$; table 4). We can deduce from score distributions in table 3 that VAC is also different from the two other RP groups. For depression, difference was shown between VAC and VA2 ( $\mathrm{p}=0.0033$; table 4$)$, suggesting a difference between groups VAC and VA1 according to the scores in table 3. 
Table 4. Results of post hoc tests (Mann-Whitney) comparing CS between VA groups and control group

\begin{tabular}{lllllc}
\hline Between groups & VA1-VA2 & VA1-VA3 & VA2-VA3 & VA2-VAC & VA3-VAC \\
\hline CS & $0.0047^{*}$ & - & 0.109 & - & $<0.001^{*}$ \\
Anxiety & - & 0.503 & - & - & $0.0065^{*}$ \\
Depression & - & 0.055 & - & $0.0033^{*}$ & 0.081 \\
\hline
\end{tabular}

RP VA groups: VA1, VA $<0.3$; VA2, $0.3<\mathrm{VA} \leq 0.7$; VA3, VA $>0.7$; VAC $=$ control group. $*$ Significance threshold: $\mathrm{p}<0.0167$ for CS and depression score and $\mathrm{p}<0.025$ for anxiety score.

Table 5. CS in VA-VF subgroups

\begin{tabular}{lllll}
\hline Groups & VA1 & VA2 & VA3 & Kruskal-Wallis test \\
\hline VF1 & $(\mathrm{n}=8)$ & $(\mathrm{n}=7)$ & $(\mathrm{n}=5)$ & 0.460 \\
& $34.28[9.83]$ & $43.03[16.72]$ & $48.83[22.44]$ & \\
\hline VF2 & $(\mathrm{n}=5)$ & $(\mathrm{n}=4)$ & $(\mathrm{n}=11)$ & $0.021^{*}$ \\
\hline VF3 & $27.77[17.58]$ & $52.51[20.28]$ & $62.80[13.47]$ & \\
& $(\mathrm{n}=2)$ & $(\mathrm{n}=11)$ & $(\mathrm{n}=7)$ & 0.175 \\
\hline Kruskal-Wallis test & 0.234 & $60.80[12.97]$ & $72.77[24.70]$ & \\
\hline
\end{tabular}
0.05 .

Values are presented as medians with interquartile ranges in square brackets. ${ }^{*}$ Significance threshold: $\mathrm{p}<$

CS medians based on VF groups and VA groups are shown in table 5 with the results from the Kruskal-Wallis test comparing subgroups. Within VF groups, a significant difference between CS of VA subgroups was only revealed for group VF2 $(p=0.021)$. Within VA groups, a significant difference between CS of VF subgroups was shown for the groups VA2 $(\mathrm{p}=0.048)$ and VA3 $(\mathrm{p}=$ $0.016)$.

\section{Discussion and Conclusion}

VF and VA are considered the most influential psychophysical parameters impacting a patient's daily life [6-9]. Szlyk et al. [6] have shown that a patient's difficulties in performing everyday activities were correlated with VF and VA, and that the patient's self-assessments were more strongly related to the VA factor. Similar correlations between the NEI-VFQ-25 scores and the American Medical Association's functional visual scores were reported by Seo et al. [7], showing that both VA and VF are important factors impacting QOL. Sugawara et al. [8] studied the effects of VF loss on the QOL of RP patients with preserved VA $(\geq 0.7)$ and demonstrated a significant negative correlation between the peripheral visual field loss and vision-related QOL scores (NEI-VFQ-25). Similar were the correlations between VF impairment and QOL in patients with low VA $(\leq 0.3)$ associated with various ocular diseases such as glaucoma, macular degeneration, diabetic retinopathy and RP [9].

The results of our study are consistent with those of these previous studies. By selecting a homogeneous group of patients with a tubular VF, we have avoided the variability of the scores of QOL that could be related to residual peripheral islands of retinal sensitivity with different levels, sizes or locations. We clearly showed that, in patients with severely reduced VF or VA, the QOL is much lower than in less affected groups. These results point to a threshold size of central residual VF of a diameter of $20^{\circ}$ and a threshold level of VA of 0.3 , below which the QOL is dramatically altered. A similar VF limit has been reported by Haymes et al. [25] concerning the mobility alteration of RP patients, which explains in part the worsening of QOL scores.

When analyzing the influence of the VA and VF parameters to each other, we observed that in the group VF1
Azoulay et al. 
(smaller residual VF, regardless of the VA level), the CS did not differ. Similarly, in the group with VA below 0.3 (VA1), regardless of the VF size, the QOL scores did not change. Thus, it appears that when a parameter is very low, the improvement of the other parameter should have little or no impact on the QOL of patients.

Independently from the degree of vision loss, being sick can affect patient QOL due to the perception of his or her abilities to perform certain daily activities. Some previous studies have correlated the QOL scores with the emotional state of patients. Owsley and McGwin [26] suggested that depressed patients may have low NEI-VFQ-25 scores independently of the impact of vision problems. For Hahm et al. [27], there was a negative correlation between the depression score (Beck Depression Inventory scale) and the NEI-VFQ-25 CS; however, the Beck Depression Inventory score was not correlated with any objective measure of visual function. It seems that it is also important to consider emotional states because they can affect the variability of visual inspections. Indeed, the variability of VF and VA measures is partly related to the severity of the disease, but these can also vary due to stress and anxiety generated by the evaluation of visual performance itself, especially on patients whose emotional state is affected by visual loss [28-30]. This is even truer when RP is in advanced and severer stages [31]. Thus, the results of ophthalmic tests and the emotional states of RP patients influence each other. Some authors, such as Rozanski et al. [30], have attempted to counter this bias; they developed a theoretical model showing that VF variability is linked to the patients' negative emotional states, providing a basis for the development of coping strategies resolving this problem.

The results of the present work show that RP has a major impact on a patient's emotional state, and this is even more pronounced when the degree of visual impairment becomes greater. In our study, patients with VF diameters less than $20^{\circ}$ (group VF1) and VA less than 0.3 (group VA1) report anxiety and depression significantly higher than the control group, thus confirming previously found thresholds.

Numerous studies have evaluated the natural course of visual field progression in RP patients and discovered the various time periods over which half of the remaining field area would be lost (half-life) [32-36]. Their results showed half-lives ranging from 4.5 years [33] to 11 years [32]. It would be interesting in future studies to specify this loss rate according to genetics in order to better predict the visual prognosis of patients and include the pro- gression profile as an important patient selection criterion for clinical trials.

In conclusion, the results of our study confirm that QOL is influenced by having RP, and it correlates in a significant way with the VF size and the VA impairment. Furthermore, they suggest a threshold approximation (VF diameter of $20^{\circ}$ and VA equal to 0.3 ) below which QOL is very deteriorated and the emotional state is highly affected. Thresholds that could represent the minimal therapeutic effects have to be targeted by therapists aiming at visual restoration, or not to be reached by those aiming at preservation. Translating a functional benefit, induced by a therapeutic action in terms of improvement of QOL, is indeed determinant.

Subjective and objective data can facilitate the doctorpatient dialogue [37-39] and help multidisciplinary teams of specialized therapists to adapt appropriate strategies for patient reeducation/readaptation and social compensations [40, 41].

\section{Acknowledgments}

This project was supported by the Foundation Fighting Blindness (FFB center grant C-CMM-0907-0428-INSERM04, C-CL0912-0600-INSERM01), Ville de Paris and Région Ile-de-France, and LABEX LIFESENSES (reference ANR-10-LABX-65).

\section{Conflicts of Interest}

All the authors hereby certify that there are no conflicts of interest with any financial issue.

References

Bunker CH, Berson EL, Bromley WC, Hayes RP, Roderick TH: Prevalence of retinitis pigmentosa in Maine. Am J Ophthalmol 1984;97: 357-365.

2 Haim M: Epidemiology of retinitis pigmentosa in Denmark. Acta Ophthalmol Scand Suppl 2002;233:1-34.

- 3 Dryja TP, McGee TL, Reichel E, Hahn LB, Cowley GS, Yandell DW, et al: A point mutation of the rhodopsin gene in one form of retinitis pigmentosa. Nature 1990;343:364-366.

-4 Hartong DT, Berson EL, Dryja TP: Retinitis pigmentosa. Lancet 2006;368:1795-1809.

5 Ayuso C, Millan JM: Retinitis pigmentosa and allied conditions today: a paradigm of translational research. Genome Med 2010;2:34.

6 Szlyk J, Fishman G, Grover S, Revelins B, Derlacki D: Difficulty in performing everyday activities in patients with juvenile macular dystrophies: comparison with patients with retinitis pigmentosa. Br J Ophthalmol 1998;82: $1372-1376$ 
7 Seo JH, Yu HG, Lee BJ: Assessment of functional vision score and vision-specific quality of life in individuals with retinitis pigmentosa. Korean J Ophthalmol 2009;23:164-168.

8 Sugawara T, Hagiwara A, Hiramatsu A, Ogata K, Mitamura Y, Yamamoto S: Relationship between peripheral visual field loss and vision-related quality of life in patients with retinitis pigmentosa. Eye Lond Engl 2010;24: 535-539.

-9 Yanagisawa M, Kato S, Kobayashi M, Watanabe M, Ochiai M: Relationship between vision-related quality of life and different types of existing visual fields in Japanese patients. Int Ophthalmol 2012;32:523-529.

10 Girmens JF, Mohand-Said S, Sahel JA: Un exemple de Centre d'Investigation Clinique dédié à l'ophtalmologie. J F Ophtalmol 2008; annexe dossier thématique. zotero://attachment/17/.

11 Goldmann H: Grundlagen exakter Perimetrie. Ophthalmologica 1945;109:59-70.

-12 Mangione CM, Lee PP, Pitts J, Gutierrez P, Berry S, Hays RD: Psychometric properties of the National Eye Institute Visual Function Questionnaire (NEI-VFQ). NEI-VFQ Field Test Investigators. Arch Ophthalmol 1998; 116:1496-1504.

13 Massof RW, Rubin GS: Visual function assessment questionnaires. Surv Ophthalmol 2001;45:531-548.

14 Varma R, Wu J, Chong K, Azen SP, Hays RD; Los Angeles Latino Eye Study Group: Impact of severity and bilaterality of visual impairment on health-related quality of life. Ophthalmology 2006;113:1846-1853.

-15 Finger RP, Fleckenstein M, Holz FG, Scholl HPN: Quality of life in age-related macular degeneration: a review of available visionspecific psychometric tools. Qual Life Res 2008; 17:559-574.

16 Revicki DA, Rentz AM, Harnam N, Thomas VS, Lanzetta P: Reliability and validity of the National Eye Institute Visual Function Questionnaire-25 in patients with age-related macular degeneration. Invest Ophthalmol Vis Sci 2010;51:712-717.

17 Orr P, Rentz AM, Margolis MK, Revicki DA, Dolan CM, Colman S, et al: Validation of the National Eye Institute Visual Function Questionnaire-25 (NEI VFQ-25) in age-related macular degeneration. Invest Ophthalmol Vis Sci 2011;52:3354-3359.
18 Lloyd AJ, Loftus J, Turner M, Lai G, Pleil A: Psychometric validation of the visual function questionnaire-25 in patients with diabetic macular edema. Health Qual Life Outcomes 2013;11:1-11.

19 Nordmann J-P, Viala M, Sullivan K, Arnould B, Berdeaux G: Psychometric Validation of the National Eye Institute Visual Function Questionnaire-25 (NEI VFQ-25) French version: in a population of patients treated for ocular hypertension and glaucoma. Pharmacoeconomics 2004;22:197-206.

20 Suzukamo Y, Oshika T, Yuzawa M, Tokuda Y, Tomidokoro A, Oki K, et al: Psychometric properties of the 25-item National Eye Institute Visual Function Questionnaire (NEI VFQ-25), Japanese version. Health Qual Life Outcomes 2005;3:65.

21 Snaith RP: The Hospital Anxiety and Depression Scale. Health Qual Life Outcomes 2003; $1: 29$.

22 Herrmann C: International experiences with the Hospital Anxiety and Depression Scale - a review of validation data and clinical results. J Psychosom Res 1997;42:17-41.

23 Bjelland I, Dahl AA, Haug TT, Neckelmann D: The validity of the Hospital Anxiety and Depression Scale. An updated literature review. J Psychosom Res 2002;52:69-77.

24 Lepine JP, Godchau M, Brun P: Anxiety and depression in inpatients. Lancet 1985;326: 1425-1426.

25 Haymes S, Heyes A, Johnston A: Mobility of People with Retinitis Pigmentosa as a Function of vision and psychological variables. Optom Vis Sci 1996. http://journals.lww. com/optvissci/Fulltext/1996/10000/Mobility_of_People_with_Retinitis_Pigmentosa_ as_a.1.aspx (accessed June 11, 2014).

26 Owsley C, McGwin G Jr: Depression and the 25-item National Eye Institute Visual Function Questionnaire in older adults. Ophthalmology 2004;111:2259-2264.

27 Hahm B-J, Shin Y-W, Shim E-J, Jeon HJ, Seo J-M, Chung H, et al: Depression and the vision-related quality of life in patients with retinitis pigmentosa. Br J Ophthalmol 2008;92: 650-654.

28 Heckenlively JR, Yoser SL, Friedman LH, Oversier JJ: Clinical findings and common symptoms in retinitis pigmentosa. Am J Ophthalmol 1988;105:504-511.

29 Bittner AK, Ibrahim MA, Haythornthwaite JA, Diener-West M, Dagnelie G: Vision test variability in retinitis pigmentosa and psychosocial factors. Optom Vis Sci Off Publ Am Acad Optom 2011;88:1496-1506.
30 Rozanski C, Haythornthwaite JA, Dagnelie G, Bittner AK: Applying theories and interventions from behavioral medicine to understand and reduce visual field variability in patients with vision loss. Med Hypotheses 2014; 83:190-195.

31 Bittner AK, Haythornthwaite JA, DienerWest M, Dagnelie G: Worse-than-usual visual fields measured in retinitis pigmentosa related to episodically decreased general health. Br J Ophthalmol 2013;97:145-148.

- 32 Berson EL, Sandberg MA, Rosner B, Birch DG, Hanson AH: Natural course of retinitis pigmentosa over a three-year interval. Am J Ophthalmol 1985;99:240-251.

33 Massof R, Finkelstein D: A two-stage hypothesis for the natural course of retinitis pigmentosa. Adv Biosci 1987;62:29-58.

34 Massof R, Dagnelie G, Benzschawel T, Palmer $\mathrm{R}$, Finkelstein D: First order dynamics of visual field loss in retinitis pigmentosa. Clin Vis Sci 1990;5:1-26.

35 Holopigian K, Greenstein V, Seiple W, Carr RE: Rates of change differ among measures of visual function in patients with retinitis pigmentosa. Ophthalmology 1996;103:398-405.

36 Grover S, Fishman GA, Anderson RJ, Alexander KR, Derlacki DJ: Rate of visual field loss in retinitis pigmentosa. Ophthalmology 1997; 104:460-465.

37 Lacasse Y, Sériès F: Qualité de vie liée à la santé: un guide de lecture. Rev Mal Respir 2004; 21:63-70.

38 Greenberg G: Beyond the blindfold: my life with retinitis pigmentosa. Clin Dermatol 2005;23:640-642, discussion 642-643.

39 Bittner AK, Edwards L, George M: Coping strategies to manage stress related to vision loss and fluctuations in retinitis pigmentosa. Optom St Louis Mo 2010;81:461-468.

40 Fintz A-C, Gottenkiene S, Speeg-Schatz C: Qualité de vie des déficients visuels adultes après prise en charge en consultation basse vision: une étude pilote. J Fr Ophtalmol 2011; 34:526-531.

41 Szlyk JP, Fishman GA, Alexander KR, Revelins BI, Derlacki DJ, Anderson RJ: Relationship between difficulty in performing daily activities and clinical measures of visual function in patients with retinitis pigmentosa. Arch Ophthalmol 1997;115:53-59. 